\title{
DESAIN SISTEM MONITORING KELUARAN GENERATOR MAGENT PERMANEN PADA SEPEDA STATIS DENGAN MIKROKONTROLER
}

\author{
Hasyim Asy’ari, Abdul Basith, Agung Aristiyanto \\ Jurusan Teknik Elektro Fakultas Teknik Universitas Muhammadiyah Surakarta \\ Jl. A. Yani Tromol Pos 1 Pabelan Kartasura 57102 Telp 0271717417 \\ Email: Hasyim.Asyari@ums.ac.id
}

\begin{abstract}
ABSTRAKSI
Perkembangan industri dan meningkatnya jumlah penduduk dunia memberikan efek yang sangat signifikan, berupa peningkatan permintaan energi listrik oleh masyarakat industri dan rumah tangga. Peningkatan permintaan tersebut harus dibarengi dengan penambahan jumlah pembangkit agar tidak terjadi overload. Pembangunan pembangkit yang menggunakan bahan bakar primer berupa gas dan batubara akan menyebabkan semakin menipisnya cadangan minyak mentah dan juga cadangan batubara, dari permasalahan tersebut perlu adanya kajian pemanfaatan energi terbarukan dan energi alternative, sebagai contoh saat ini masyarakat semakin banyak memanfaatkan alat fitnes center untuk berolahraga agar senantiasa kondisi tubuh senantiasa segar dan bugar, namun pemanfaatan alat fitnes tersebut sebatas untuk menjaga kondisi kesehatan tubuh. Jika dilihat alat sepeda statis maka ada potensi untuk menghasilkan energi listrik sehingga selain menjaga kondisi tubuh dapat juga memproduksi energi listrik.

Penelitian ini bertujuan untuk merancang pembaca RPM dan tegangan yang dihasilkan oleh generator magnet permanen yang dipasang pada sepeda statis. Sehingga pada saat mengkayuh sepeda statis maka roda sepeda akan bergerak atau berputar, perputaran roda tersebut dihubungkan dengan rotor generator magnet permanen sehingga rotor tersebut akan berputar pula, perputaran tersebut mengakibatkan adanya tegangan keluaran pada generator magnet permanen, agar pengguna sepeda status mudah memantai keluaran generator magnet tersebut maka dilakukan pengukuran berupa kecepatan putar rotor PMG dan juga tegangan keluaran dengan memanfaatkan sensor infrared, sensor photodioda, dan sensor pembagi tegangan yang outpunya akan diolah oleh minimum sistem Atmega16. Alat ini juga dilengkapi baterai yang berguna untuk menyalakan alat ketika alat digunakan pada suatu tempat yang belum ada listrik PLN.

Hasil penelitian ini adalah sebuah alat pembaca RPM dan tegangan generator magnet permanen yang penggerak utama adalah kayuhan user. Pembacaan nilai RPM ini diperoleh dari pembacaan sensor photodioda yang dirangkai dengan sensor infrared, sedangkan pada tegangan ini dibaca nilainya dari sensor pembagi tegangan. Alat ini memiliki kapasitas maksimal tegangan yang dapat dibaca yaitu 20 volt DC. Baterai $9 \mathrm{~V}$ dapat digunakan ketika listrik PLN sedang padam atau ketika tidak tersedia energi listrik PLN. Hasil nilai dari alat ini dibadingkan dengan nilai dari alat multimeter dan tachometer infrared, yang menghasilkan nilai perbandingan pada alat yang dibuat untuk mengukur tegangan 13,04V, sedangkan pada multimeter menujukkan nilai tegangan 12,80V dengan selisih perbadingan 1,87\%, alat yang dibuat selalu lebih tinggi nilainya. Pada pengukuran RPM alat yang dibuat menujukkan nilai 1249,25 RPM, sedangkan pada tachometer digital infrared 1262,64 RPM dengan selisih perbandingan 1,10\%, alat yang dibuat perhitungannya selalu lebih tinggi dari alat yang ada.
\end{abstract}

Kata Kunci : Atmega16, Sensor Infrared, Sensor Photodioda, Sensor pembagi tegangan

\section{PENDAHULUAN}

Perkembangan industri dan meningkatnya jumlah penduduk dunia memberikan efek yang sangat signifikan, berupa peningkatan permintaan energi listrik oleh masyarakat industri dan rumah tangga. Peningkatan permintaan tersebut harus dibarengi dengan penambahan jumlah pembangkit agar tidak terjadi overload. Pembangunan pembangkit yang menggunakan bahan bakar primer berupa gas dan batubara akan menyebabkan semakin menipisnya cadangan minyak mentah dan juga cadangan batubara, dari permasalahan tersebut perlu adanya kajian pemanfaatan energi terbarukan dan energi alternative, sebagai contoh saat ini masyarakat semakin banyak memanfaatkan alat fitnes center untuk berolahraga agar senantiasa kondisi tubuh senantiasa segar dan bugar, namun pemanfaatan alat fitnes tersebut sebatas untuk menjaga kondisi kesehatan tubuh. Jika dilihat alat sepeda statis maka ada potensi untuk menghasilkan energi listrik sehingga selain 
menjaga kondisi tubuh dapat juga memproduksi energi listrik.

Energi terbarukan perlu dioptimalkan sebagai upaya untuk mengurangi ketergantungan penggunaan bahan bakar fosil. Kajian-kajian tersebut dengan berbagai skema tergantunga dari potensi alam yang dimanfaatkan. Pemanfaatan tenaga air dan angin merupakan potensi alam yang sedang popular dilakukan. Banyak sekali penelitian tentang pembuatan kincir angin dan kincir air untuk memanfaatkan potensi angin dan air yang akan dikonversi menjadi energi listrik. Kedua jenis kincir ini pasti membutuhkan generator untuk merubah energi mekanis menjadi energi listrik yang disebut generator. Generator yang tersedia biasanya berjenis high speed induction generator, generator jenis ini membutuhkan putaran tinggi dan membutuhkan energi listrik awal untuk membuat medan magnetnya. Sedangkan pada penggunaan kincir angin di butuhkan generator yang berjenis low speed dan tanpa energi listrik awal, karena biasanya di tempatkan di daerah-daerah yang tidak memiliki aliran listrik.

Penerapan inovasi teknologi yang menggunakan energi terbarukan akan membantu kegiatan manusia dan bersifat ramah lingkungan. Perkembangan yang seperti itu bisa diwujudkan dalam bidang olahraga (gym) yang pada akhirnya dapat memberikan kemudahan dalam memperoleh sumber energi terbarukan.

Sepeda statis adalah sebuah peralatan olahraga yang ramah lingkungan. Di desain untuk mengurangi kecendrungan manusia dalam olahraga yang menggunakan sumber energi listrik. Generator sebagai pembangkit listrik dengan penggerak kayuhan pedal sepeda statis yang kemudian mengisi akumulator dan motor akan menggerakan gearbok dengan menggunakan sumber listrik dari akumulator tersebut (Hasyim, 2014).

Pemanfaatan sepeda statis dan generator magnet permanen memberikan keluaran 15,8 Volt dan arus $250 \mathrm{~mA}$ dengan putaran rotor generator tersebut mencapai $1150 \mathrm{rpm}$ (Hasyim, 2014).

\section{METODE PENELITIAN}

2.1 Alat dan Bahan Penelitian

Alat dan Bahan yang dibutuhkan untuk membuat alat ini adalah :

a. Mikrokontroler Atmega16.

b. Minimum sistem.

c. LCD $2 \times 16$.

d. Sensor Tegangan, Infrared, Photodioda.

e. Power Supply 5 Volt.

f. Baterai 9 Volt.

g. Keping CD.

Diagram Alir Penelitian

Proses penelitian dan perancangan dilakukan dengan berbagai tahap dan proses sehingga mendapatkan data dan informasi lengkap.

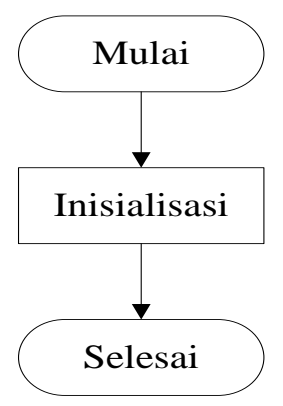

Gambar 1. Diagram alir inialisasi.

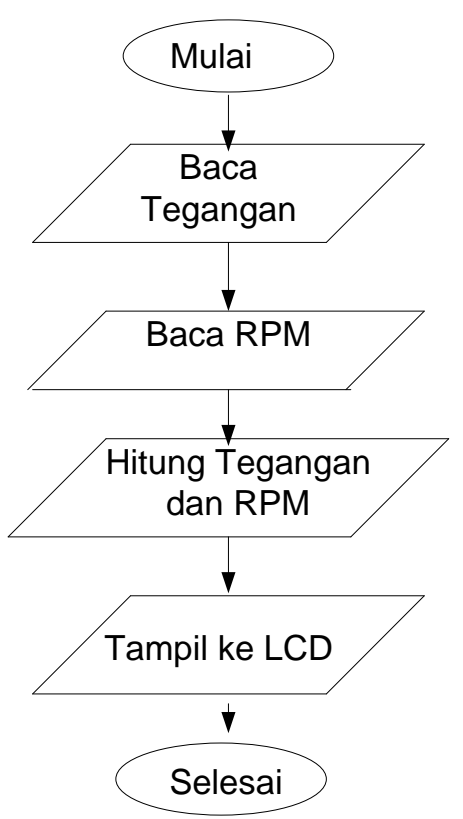

Gambar 2. Diagram alir program keseluruhan.

Perancangan alat penampil RPM dan tegangan pada generator magnet permanen sepeda statis. 


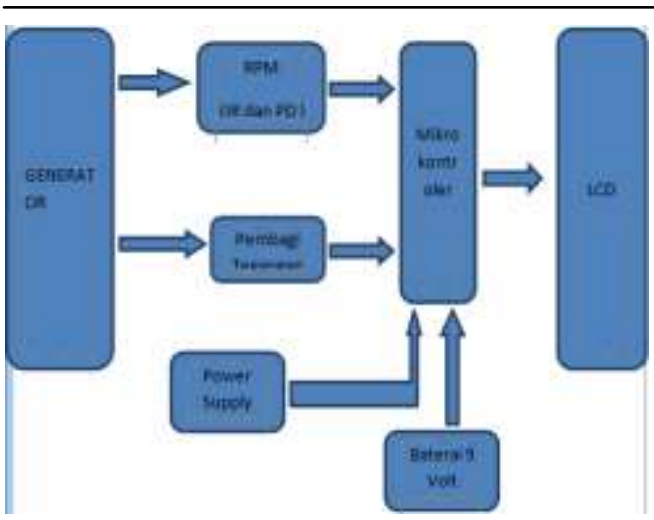

Gambar 3. Diagram rangkaian.

Perancangan hardware :

1. Minimum system.

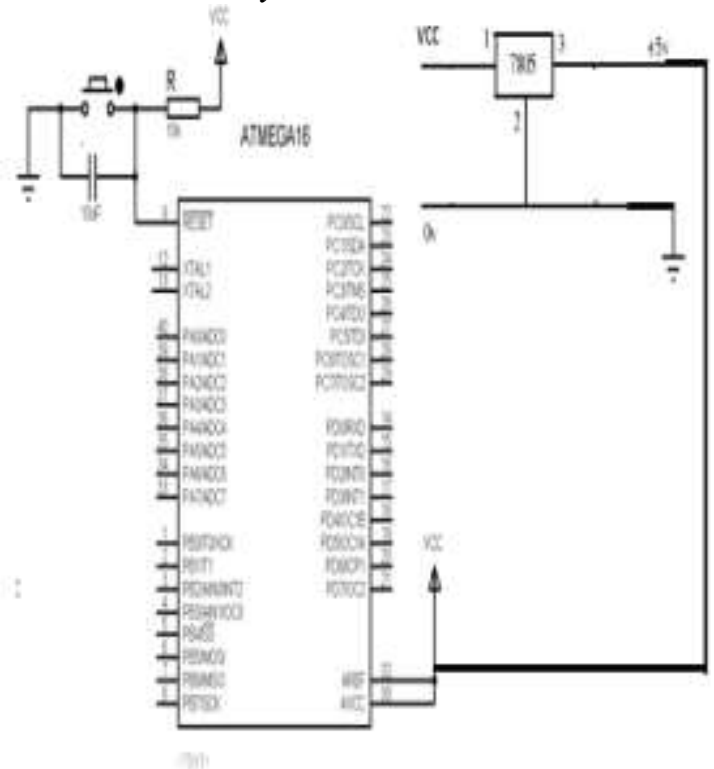

Gambar 4. Skema minimum system.

2. LCD $16 \times 2$.

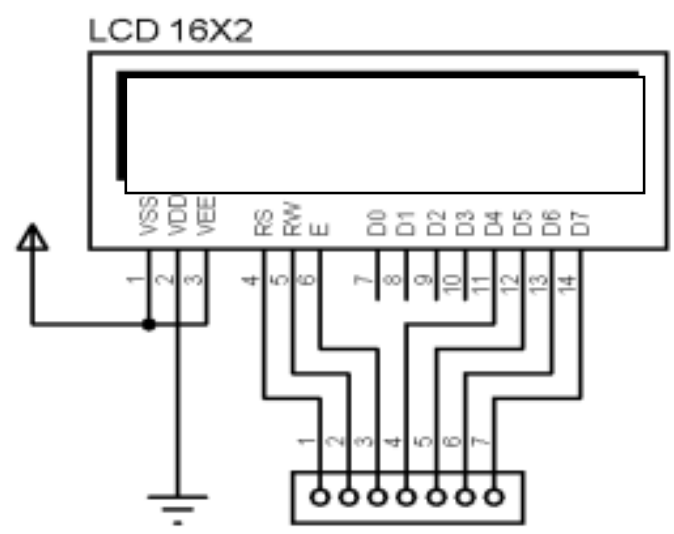

Gambar 5. Skema LCD 16x2.

3. Rangkaian sensor pembagi tegangan.

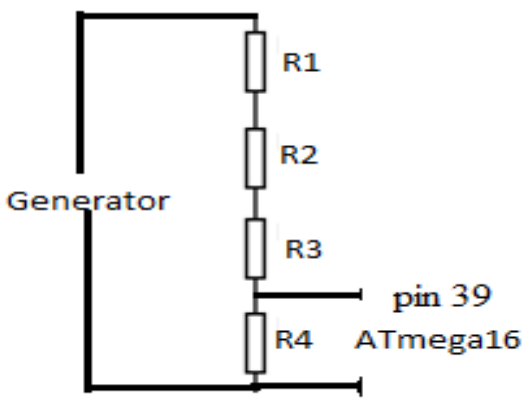

Gambar 6. Skema pembagi tegangan.

4. Rangkaian sensor pembaca RPM yang terdiri dari sensor infrared dan sensor photodioda.

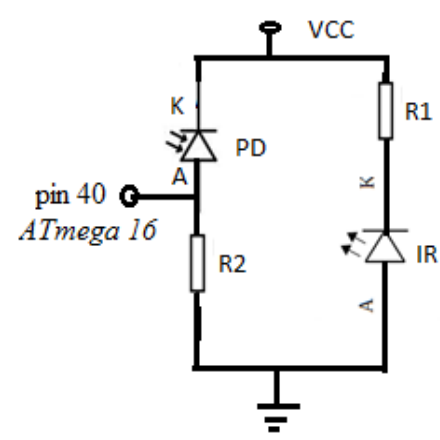

Gambar 7. Skema pembaca RPM.

5. Baterai 9volt dan Switch.

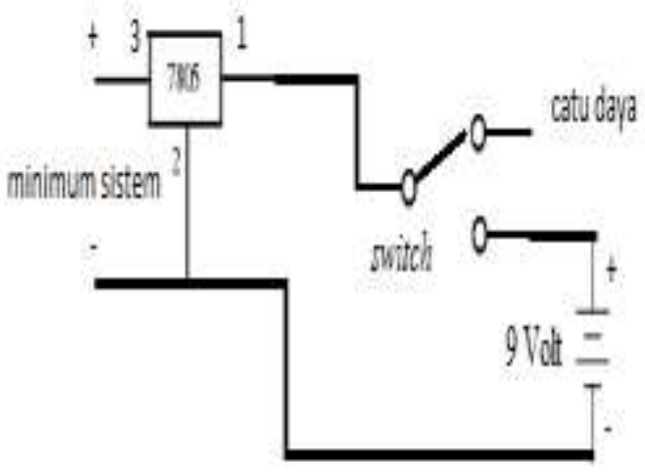

Gambar 8. Skema baterai 9V dan switch.

6. push button.

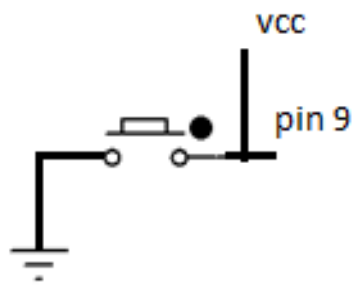

Gambar 9. Skema rangkaian reset. Perancangan software :

1. Software proteus v7.5SP3.

2. Software codevision AVR.

Software diptrace v2.3.1. 


\section{HASIL DAN PEMBAHASAN}

Pada penelitian ini mendesain alat ukur penampil RPM dan tegangan berbasis mikrokontroler tipe Arduino, hasil desain akan digunakan untuk mengukur tegangan keluaran dan kecepatan putar generator magnet permanen pada sepeda statis, untuk mengetahui keakuratan alat tersebut maka hasilnya dibandingkan dengan peralatan tachometer dan voltmeter.

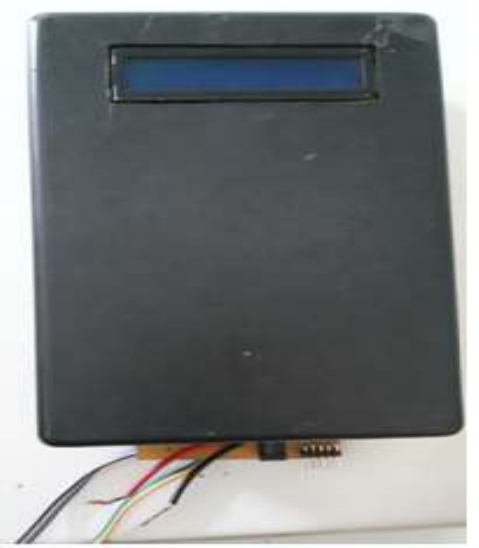

Gambar 10. Bentuk box dari depan.

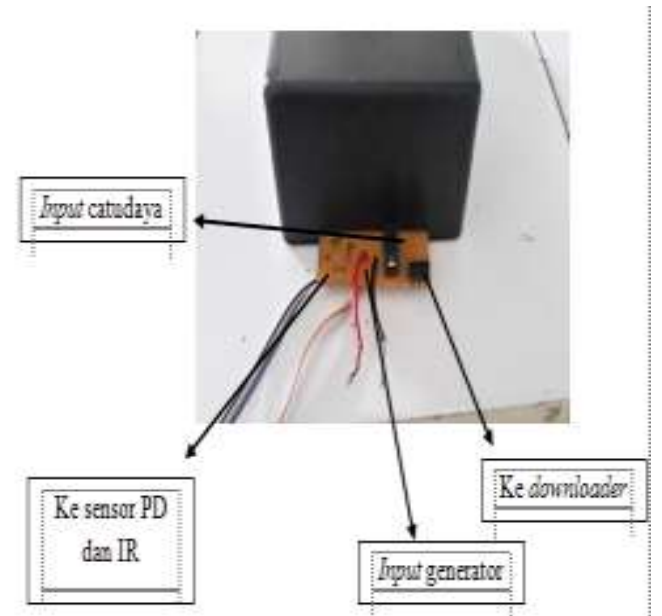

Gambar 11. Bentuk box dari bagian samping.

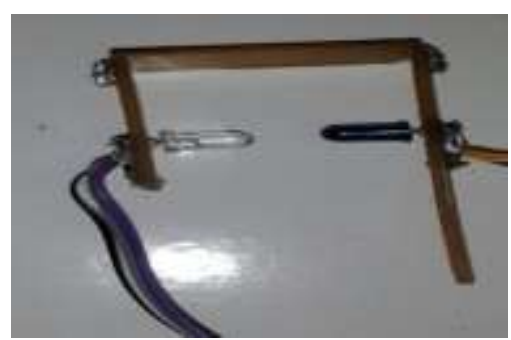

Gambar 12. Sensor Photodioda dan Sensor infrared.

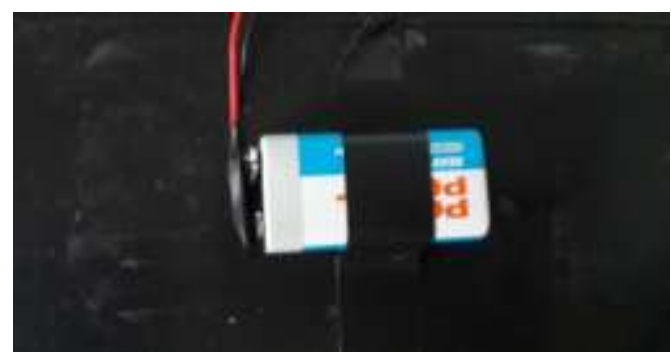

Gambar 13. Baterai 9 Volt.

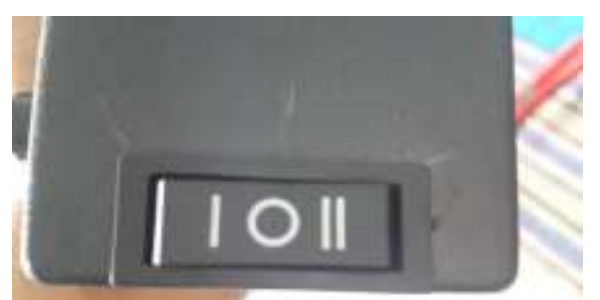

Gambar 14. Sakelar baterai atau catu daya.

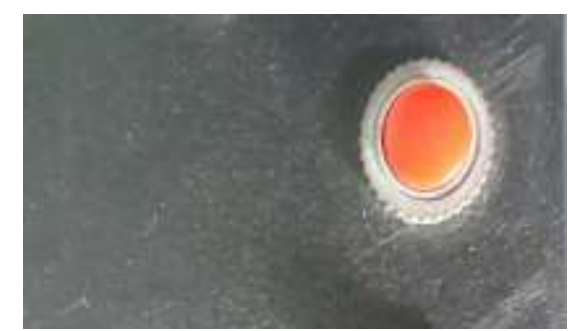

Gambar 15. Push button untuk reset.

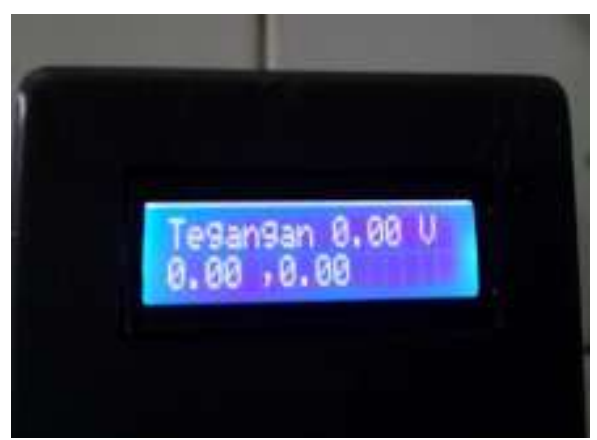

Gambar 16. Tampilan awal.

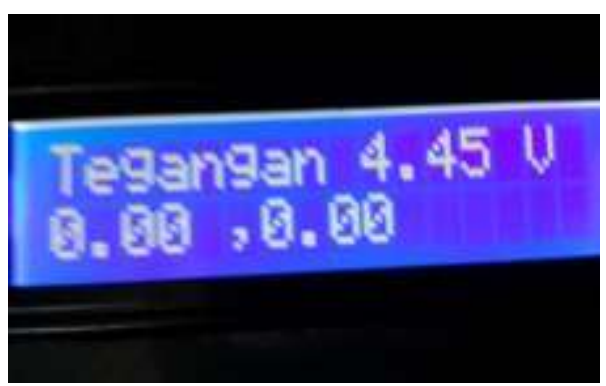

Gambar 17. Tampilan Tegangan. 


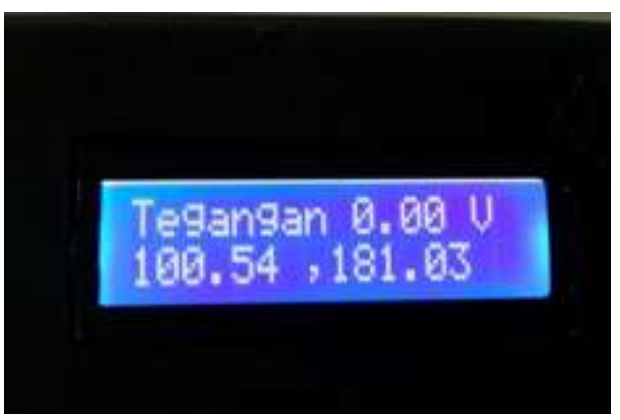

Gambar 18. Tampilan RPM.

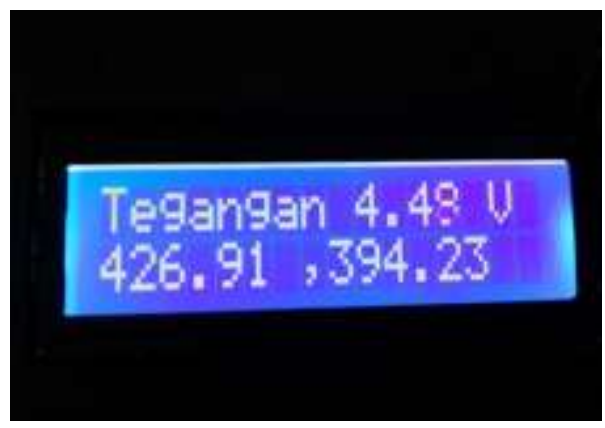

Gambar 19. Tampilan RPM dan Tegangan.

Hasil Ujicoba yang telah didapat pada penelitian alat ditunjukkan pada tabel 1 .

Tabel 1. Hasil Pengujian Tegangan.

\begin{tabular}{cccc}
\hline No & \multicolumn{2}{c}{ Tegangan } & Selisih \\
& Multimeter & $\begin{array}{c}\text { Alat yang } \\
\text { dibuat }\end{array}$ & $(\%)$ \\
\hline 1 & 5,98 & 6,38 & 6,68 \\
2 & 8,56 & 8,86 & 3,51 \\
3 & 9,97 & 10,25 & 2,81 \\
4 & 12,80 & 13,04 & 1,87 \\
5 & 17,66 & 17,93 & 1,61 \\
\hline
\end{tabular}

Data pada tabel 1 memberikan informasi bahwa tegangan yang terukur oleh alat yang dibuat memiliki selisih dengan voltmeter tertinggi adalah $6,68 \%$ dan terendah adalah $1,61 \%$,

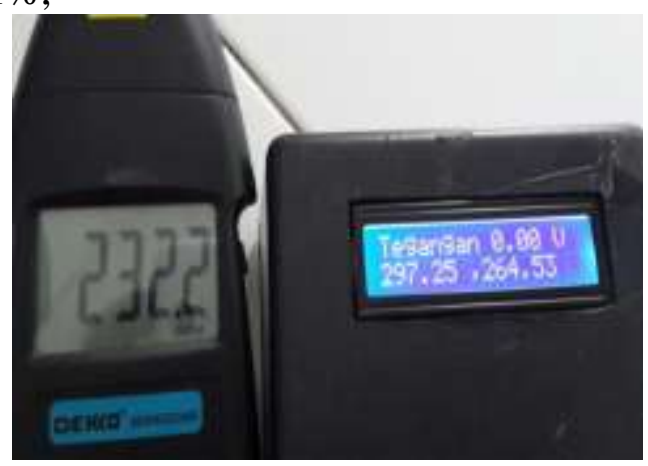

Gambar 20. Pengujian RPM.
Tabel 2. Hasil Pengujian RPM

\begin{tabular}{cccc}
\hline No & \multicolumn{2}{c}{ Tegangan } & Tachome \\
ter & $\begin{array}{c}\text { Alat yang } \\
\text { dibuat }\end{array}$ & $\begin{array}{c}\text { Selisih } \\
(\%)\end{array}$ \\
\hline 1 & 249,2 & 264,53 & 6,15 \\
2 & 452,35 & 484,45 & 7,09 \\
3 & 645,12 & 662,93 & 2,76 \\
4 & 798,55 & 828,80 & 3,78 \\
5 & 1249,25 & 1262,64 & 1,10 \\
\hline
\end{tabular}

Data pengujian pada tabel 2 menunjukkan bahwa selisih tertinggi antara alat yang dibuat dan tachometer sebesar $7,09 \%$ dan terendah adalah $1,1 \%$.

1. Pengujian RPM dan Tegangan.

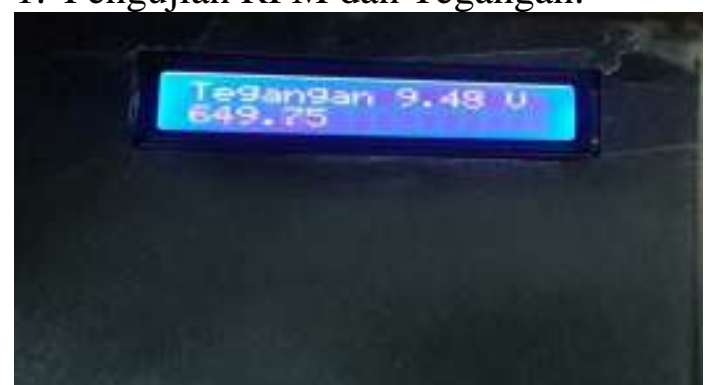

Gambar 21. Pengujian RPM dan Tegangan.

Tabel 3. Hasil Pegujian RPM dan Tegangan.

\begin{tabular}{ccc}
\hline No & $\begin{array}{c}\text { Kecepatan Putar } \\
\text { (RPM) }\end{array}$ & Tegangan (Volt) \\
\hline 1 & 0 & 0 \\
2 & 100 & 1,25 \\
3 & 300 & 4,13 \\
4 & 600 & 8,33 \\
5 & 900 & 11,33 \\
6 & 1200 & 13,98 \\
7 & 1500 & 16,12 \\
\hline
\end{tabular}

\section{Hasil pengujian RPM dan Tegangan}

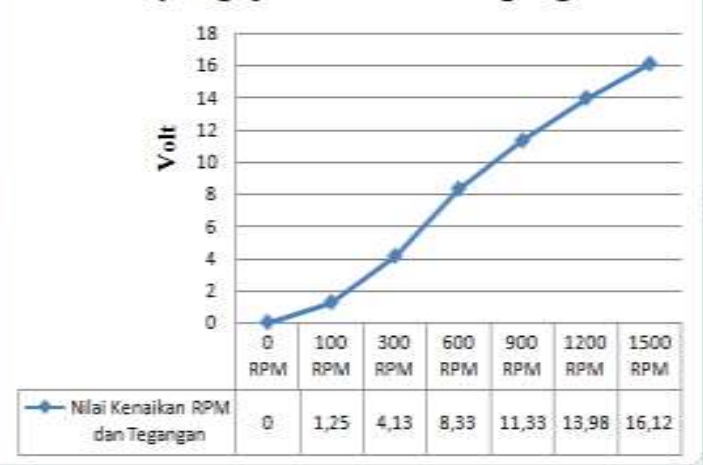

Gambar 22. Grafik Hasil Pengujian RPM dan Tegangan. 
Gambar 22 memberikan informasi bahwa kecepatan putar generator magnet permanen memberikan dampak terhadap tegangan keluaran generator tersebut. Tegangan keluaran akan meningkat sejalan dengan kenaikan kecepatan putar generator magnet permanen. Tegangan tertinggi yang dihasilkan dalam pengujian sebesar 16,12 Volt DC dengan kondisi kecepatan putar $1500 \mathrm{Rpm}$.

\section{KESIMPULAN}

Berdasarkan hasil penelitian pembuatan desain penampil RPM dan tegangan keluaran generator magnet permanen pada sepeda statis berbasis Atmega16, dapat disimpulkan sebagai berikut:

1. Penggunaan penampil RPM dan tegangan pada sepeda statis yang ditambahkan dengan generator magnet permanen kecepatan rendah ini lebih menarik, sehingga pengguna sepeda statis dapat mengerti berapa putaran RPM dan besar tegangan yang dihasilkan saat pengguna mengayuh sepeda statis. Selisih antara alat tachometer dengan desain alat maksimal $7,09 \%$.

2. Data yang terukur oleh alat yang dibuat memiliki selisih dengan voltmeter terbesar adalah $6,68 \%$. Alat ini bisa digunakan ditempat yang belum ada listrik PLN dengan menggunakan baterai $9 \mathrm{~V}$.

\section{DAFTAR PUSTAKA}

Anonim. 2010. RPM Motor DC : Menghitung Kecepatan dalam RPM, http://too- payz.blogspot.com//2010/10/rpmmotor-dc-menghitung-kecepatandalam.html?m=1/, 20 September 2010, 00:19WIB.

Bejo, Agus. 2008. C \& AVR Rahasia Kemudahan Bahasa $C$ dalam Mikrokontroler ATmega 8535. Yogyakarta : Graha Ilmu.

Febri, Acuk . 2012. Membuat Generator Magnet Permanen Kecepatan Rendah. Surakarta: Tugas Akhir. Universitas Muhammadiyah Surakarta.

Muhammad. 2014. Desain Sepeda Statis Generator Magnet Permanen. Surakarta: Tugas Akhir, Universitas Muhammadiyah Surakarta.

Munkhanif, Muhammad. 2013. Rangkaian Resistor Pembagi Tegangan, http://kanip-

fismandor.blogspot.com/2013/02/rangk aian-resistor-pembagitegangan.html?m=1/, 26 Februari 2013, 04.59 WIB.

Rahman, Arief. 2013. Desain Generator Magnet Permanen Untuk Sepeda Listrik. Surakarta: Tugas Akhir, Universitas Muhammadiyah Surakarta.

Sumardi. 2013. Mikrokontroler Belajar AVR Mulai Dari Nol. Yogyakarta : Graha Ilmu. 